\title{
Heart Rate Monitoring System During Physical Exercise for Fatigue Warning Using Non-invasive Wearable Sensor
}

\author{
$1^{\text {st }}$ Dody Ichwana \\ Dept. of Computer Engineering \\ University of Andalas \\ Padang, Indoensia \\ dody.ichwana@fti.unand.ac.id
}

\author{
$2^{\text {nd }}$ Rahmat Zaitul Ikhlas \\ Dept. of Computer Engineering \\ University of Andalas \\ Padang, Indoensia \\ rahmat.zaitul@gmail.com
}

\author{
$3^{\text {rd }}$ Shelvi Ekariani \\ Dept. of Matehematics \\ University of Andalas \\ Padang, Indoensia \\ sekariani@fimipa.unand.ac.id
}

\begin{abstract}
Exercise provides many benefits for the body. For someone who has heart problems, exercise should be aligned according to the heart condition. This paper proposes to report a system of monitoring heart rate in real time based on Android by using photoplethysmograph (ppg) signals to provide early warning in anticipation of fatigue during running exercise. The contribution of this study is an algorithm to define the level of fatigue when a user running exercise. During exercise, the heart rate monitoring system in the application will record heart rate data in real time and give a warning message in the form of vibration on the user's smartphone device when the heart rate is too fast or over the maximum limit. Monitoring heart rate using an Android application and easy pulse plug-in sensor. The easy pulse plug-in sensor is placed on the user's fingertips to record heart rate data using photoplethysmograph (ppg) signals when the user do the exercise. The heart rate detection by the easy pulse plug-in sensor is done in the microcontroller, and then the heart rate data is sent to the smartphone via Bluetooth communication media. System testing is done by running exercise using a test scenario in the form of variations in age, running speed and length of running period to see the effect of physical activity on the number of heart rates. The test results show that the accuracy of heart rate detection is $95.923 \%$ and the android application can give a warning when the user's heart rate more than the normal limit when running.
\end{abstract}

Keywords-heart rate monitoring, wearable sensor, photoplethysmograph (ppg), physical exercise, android

\section{INTRODUCTION}

Jogging provide many benefits and health for the body, including the heart. However, for people who have problems with heart, this exercise must be aligned to heart health. Health problems of heart are often unknown, because they do not show symptoms and never have a heart health check [1][2][3]. During exercise, it is recommended to monitor the condition of the heartbeat so as to reduce the risk of heart attack which can lead to death [4][5].

Information on heart rate is very important to know when doing daily activities, especiallyduring running sports [6]. The development of wearable sensor technology enable the monitoring heart rate can be performed in a portable and realtime way. The use of manual methods for calculating heart rate when running is not possible, so that required a tool that can monitor the heart rate continuously while running.

Running involves a lot of muscle and requires a lot of energy that requires more oxygen. The faster you run, the more oxygen you need and the faster blood flow in the body [1]. When running, the lungs work hard to process oxygen and the heart beats rapidly to pump blood throughout the body carrying oxygen from the lungs. After the exercise, the heart and lungs can't just suddenly move slowly because the body is still needs more oxygen supply. The pressure received by the blood vessels when running makes the heart rate when running is not the same as at rest, so that the heartbeat activity during running may make possible of occurrence the heart rate abnormalities [7].

At rest, the normal heart rate is between 60-100 BPM (beat per minute), while at running the heart rate will increase according to the level of activity performed. Heart rate has a maximum limit, for that, it is required a heart rate controlling when running. At running, the heart rate should not exceed the maximum limit. It will cause heart rate abnormalities.

A normal range of heart rate when running is $50 \%-80 \%$ of maximum heart rate. If the heart rate exceeds $80 \%$ of the maximum limit, runners will feel the pain in the body so that the physical activity must be reduced to avoid the danger due to faster heart rate. Under certain conditions, the body feels pain when the heart rate is still at the range of $60 \%-70 \%$ so that the running activities must be reduced. This condition is caused by various factors, ranging from health conditions to exercise habits [7]. The monitoring heart rate during running exercise will help to achieve optimal results when exercising. Technological developments make the use of wearable devices increasing, the use of wearable devices usually is related to smartphones [8][9][10]. At this time, the heart rate measuring device for exercise still does not have a fatigue warning feature. Most of these devices only still measure the number of heart rate.

Some studies on measuring heart rate during physical activity have been done $[11][12][13][14][15][16][17]$. However, the study still hasn't discussed giving a warning message of fatigue during physical exercise. In the research [18][19] the heart rate measurement was carried out using ppg signals and cameras, but still not using portable devices. The use of smartphones for heart rate measurements during physical activity makes it more real time [12].

This study aims to develop a system of heart rate monitoring in real time using photoplethysmograph signals to provide early warning in anticipating fatigue in running sports activities. In this paper, we propose an algorithm to measure the level of fatigue during physical exercise using the accelerometer and ppg signals. The system will monitor the heart rate when running. When the heart rate is abnormal, the application on the Android smartphone will give a warning so that the physical activity reduced.

\section{METHODOLOGY}

This study was designed using experimental research methods. The type of exercise that becomes the testing object 


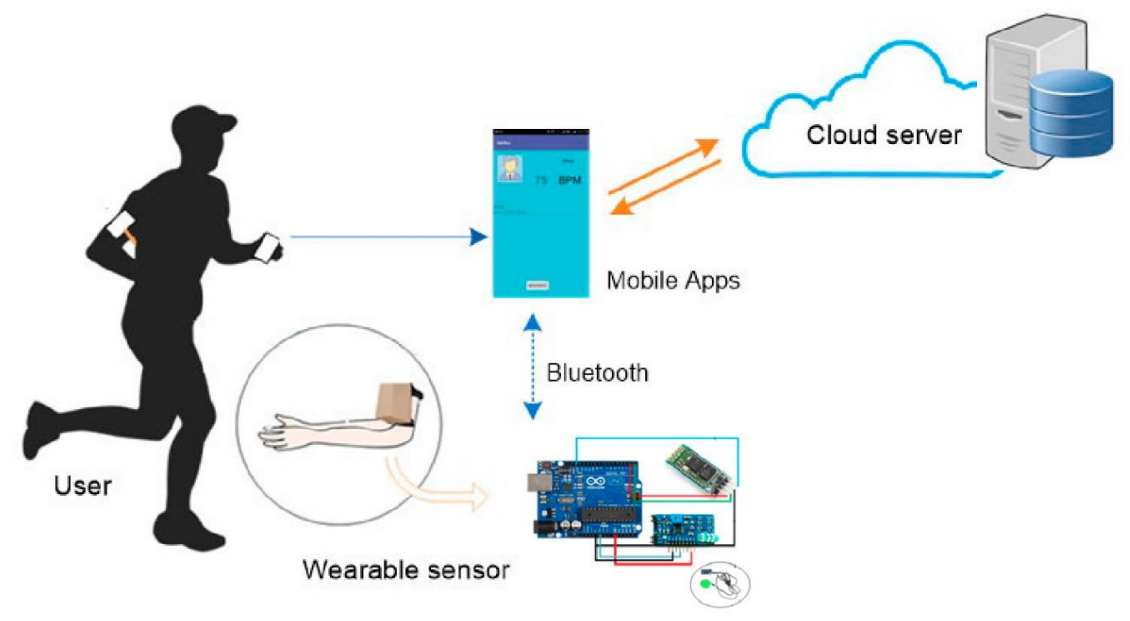

Fig. 2. Design of the system

for this research is running. In overall, the system development process includes 1) System needs analysis, 2) Designing a system model, 3) Designing a sensor device for heart rate detection, 4). Testing design

\section{A. System Needs Analysis}

The purpose of the system needs analysis is to ensure the system needs for the overall system development process. The output of this process is the functional needs of the system. Functional requirements of this system are 1) users can find out the number of heartbeats when exercising, 2) users can receive alerts and notifications if the heart rate is abnormal, 3 ) users can save heart rate data, 4) users can see the history of the heart rate. The system use case diagram can be seen in Figure 1.

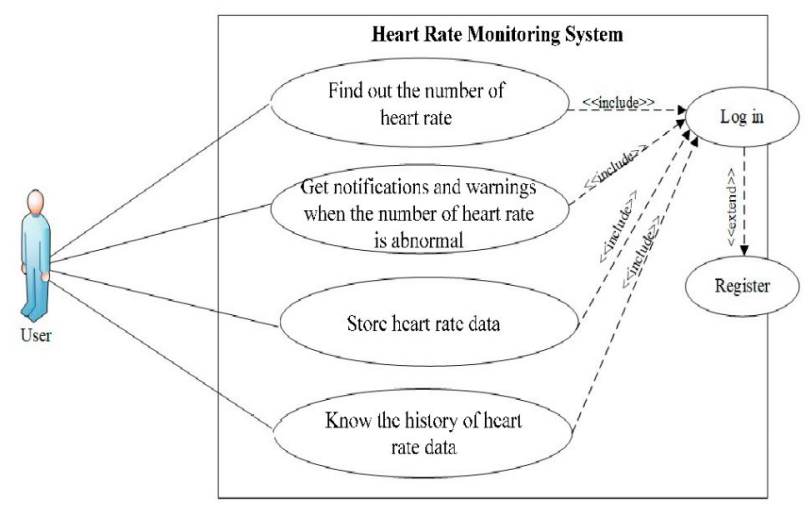

Fig. 1. Use case diagram

\section{B. Designing a System Model}

The design of the system model provides a general picture of the system to be built. This system consists of two parts, The first device is a wearable device sensor placed on fingertips user. The second device is smartphone that is used to calculate the level of fatique and display the user's heart rate. The general design of the system in this research is shown in Figure 2.

Users will receive alerts and notifications when the heart rate is not normal. Furthermore, the data that has been displayed can be sent to the web server to be stored so that it can be accessed back to see the history of heart rate activity while running.

\section{Design a Sensor Device for Heart Rate Detection}

Easy pulse plug-in sensor is used to detect heart rate using a ppg signal. This sensor is placed on user's fingertips. The module of sensor easy pulse plugin, bluetooth, Arduino microcontroller and power supply are placed in a separate box on the user's arm. Arduino uno is used as a microcontroller to process analogue signals obtained into digital signals. Based on the signal obtained heart rate data, which is then displayed on the smartphone application using Bluetooth communication media. Design of wearable device can bee seen in Figure 3.

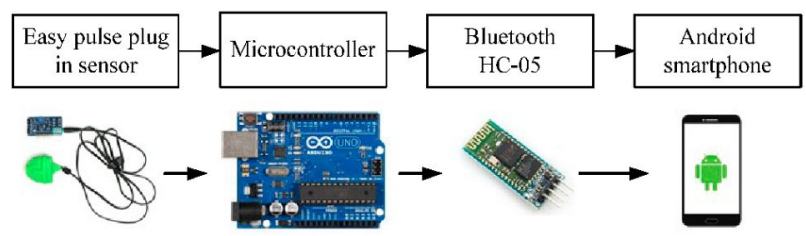

Fig. 3. Block diagram design of wearable device

\section{Experiment and Testing Setting}

The testing scenario uses seven different subjects, consisting of six men and one woman with the age range of 20-28 years. The use of this age range is aimed at research focused on an adult. the subject was not a professional athlete. For all seven subjects, conducted five times running for each user. Each subject run for $2 \mathrm{~km}$ distance using a treadmill running test. The data used in the experiment was heart rate data. The data collected were the subject's heart rate data at rest before running and the subject's heart rate data while running. While running, the subject's speed along $2 \mathrm{~km}$ running distance may vary according to the subject's want so that the running speed did not have to be constant, and it aimed to facilitate the subject in retrieving data because if constant speed was given, it would make the subject difficult for running. So as the subject could adjust the running speed according to ability and age of each user.

At the time of running, a warning message will also be considered. If the subject gets a warning message at a particular running speed, it will be seen how the effect of running speed to the subject heart rate, whether the heart rate 
will increase at a different speed. In this test, the average subject heart rate and the highest heart rate will be recorded in the database so that the subject can see it for evaluation of the next run. In addition to the heart rate, the application will record when the subject ran and how long the user ran. The process of retrieving the subject's heart rate data on a treadmill can be seen in Figure 4.
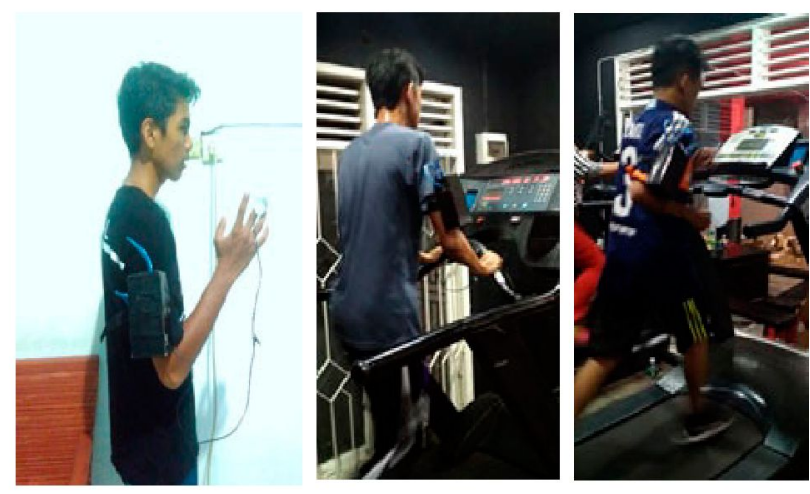

Fig. 4. The process of retrieving the subject's heart rate data on treadmill

\section{DEFINITION OF FATIGUE LEVEL}

Heart rate detection started from reading the electrical signals by a sensor that generated by the change of blood volume passing through the arteries. When the sensor is not in contact with the heart rate source, the output of the signal is at the midpoint of the voltage or $\frac{V}{2}$. When the sensor touches the pulse source, then it will change become reflected light. The change of the blood volume in the blood vessels through the tissue will make the signal fluctuate around the reference point. From this signal fluctuation, the sensor will detect the tissue or organ that moves in the artery. The signal received by the receiver circuit will be filtered using a high pass filter circuit. Then the signal will be given an amplifier through a non-inverting amplifier circuit and return to normal conditions. The form of the generated signal graph can be seen in the following Figure 5:

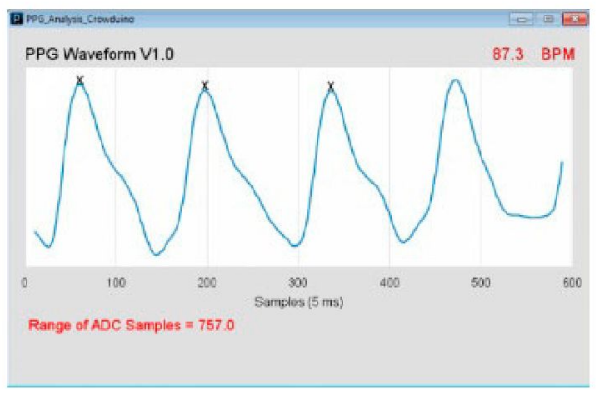

Fig. 1. Output ppg signals on easy pulse sensor

Determination of the number of heartbeats per minute (BPM) by dividing 60000 (in milliseconds) the pulse rate value of 3 consecutive peaks IBI (inter beat interval) that has been passed. IBI is the time difference between one point and the next point with the point value is $50 \%$ of the $P$ value (peak) substracted with $\mathrm{T}$ (valley) when the graph experiences a sharp increase. Heart rate calculation is obtained from equation 1 . The flowchart to detect 3 peak of ppg signals can be seen in Figure 5.

$$
\text { Heart rate }(\mathrm{BPM})=(60000 / \text { pulse rate })
$$

Pulse rate is value of three consecutive peaks IBI. Heart rate calculated from the time period of the ppg signals waveform.

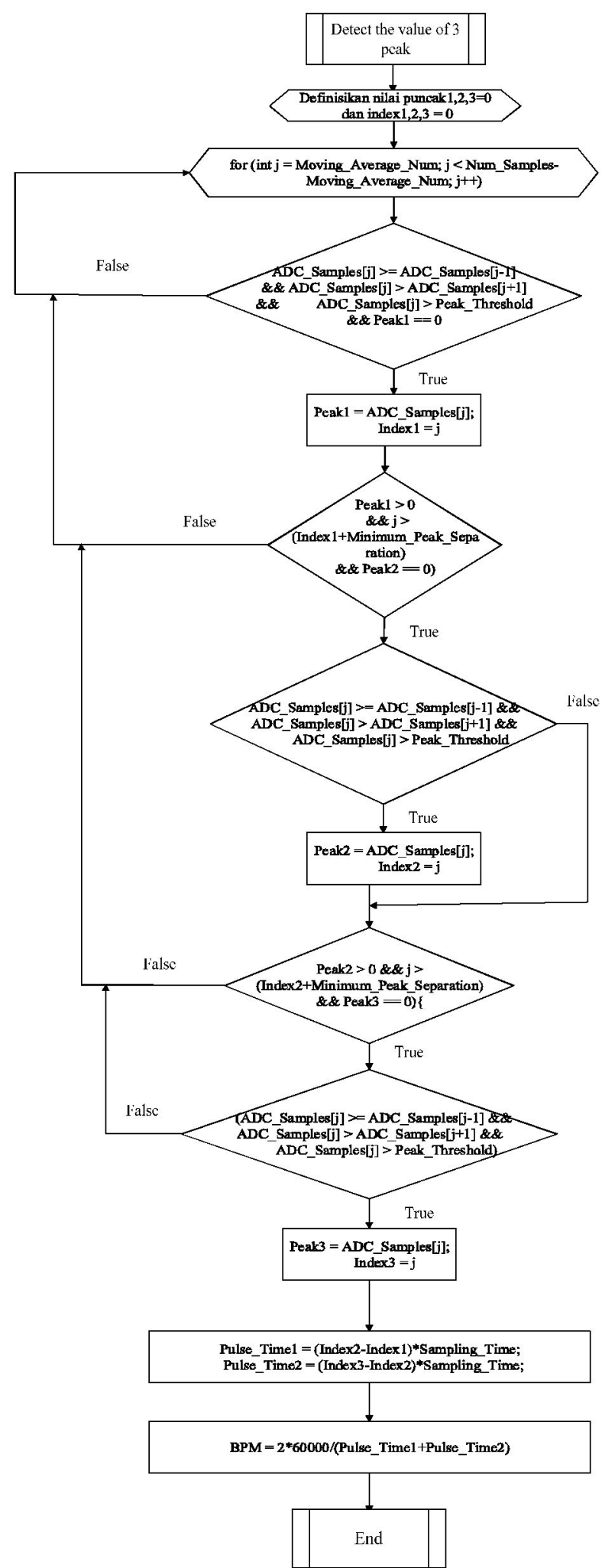

Fig. 2. Flowchart of process to detect 3 peak of ppg signals

Identification of three successive peaks in waveform based on where the slope of the curve changes from positive to negative, and the magnitude of the signal is greater than $80 \%$ 
of the total of all samples. Two heart rates are calculated from three consecutive ppg signals peaks, and their average values are displayed as heart rates.An algorithm has been built to get the definition and level of user fatigue during physical exercise. The maximum heart rate is obtained from the formula 220 - age of user. The normal heart rate during activity is $50 \%-80 \%$ of the maximum heart rate. If the heart rate is above $80 \%$ of the maximum heart rate, the subject will feel pain so physical activity must be reduced. Under certain conditions, at a heart rate of $60 \%-70 \%$ of the maximum heart rate the subject feels pain in the body part, then physical activity must also be reduced. The algorithm 1 determines the level of fatigue.

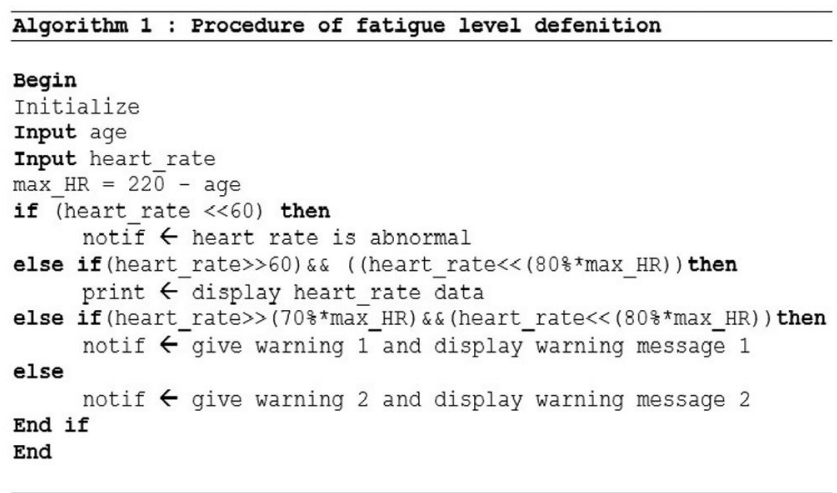

\section{RESULT AND DISCUSSION}

Wearable device is implemented using easy pulse sensor, arduino uno microcontroller and Bluetooth $\mathrm{HC}-05$. The implementation of smartphone applications on the Andorid operating system is built using Android studio. Figure 7 is showed wearable devices. In the smartphone application, the user will get the first warning notification and vibrate for 2 seconds when the heart rate is more than $70 \%$ maximum heart rate. When the user's heart rate is more than $80 \%$ the maximum heart rate will be given a second warning notification and vibrate for $\mathbf{4}$ seconds. Monitoring the number of user's heart rate during physical exercise through the smartphone application is shown in Figure 8. In Figure 9 (a) is showed a warning notification is given when the user's heart rate is abnormal by the smartphone application, Figure 9 (b) is showed the average number and number of highest heart rate during physical exercise.

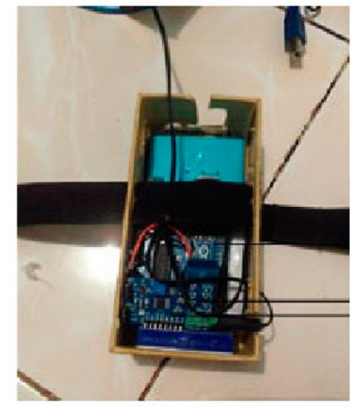

Fig. 3. Implementation of wearable device

Based on the results of the overall test, the test was carried out on seven different people with five runs per person. Each user runs for a distance of $2 \mathrm{~km}$. Running speed affects the user's heart rate where at high speed runs the heart rate also increases. The highest heart rate is obtained when the user runs at a faster speed. The test results on 7 subjects with each subject doing 5 times of run can be seen in Table I.

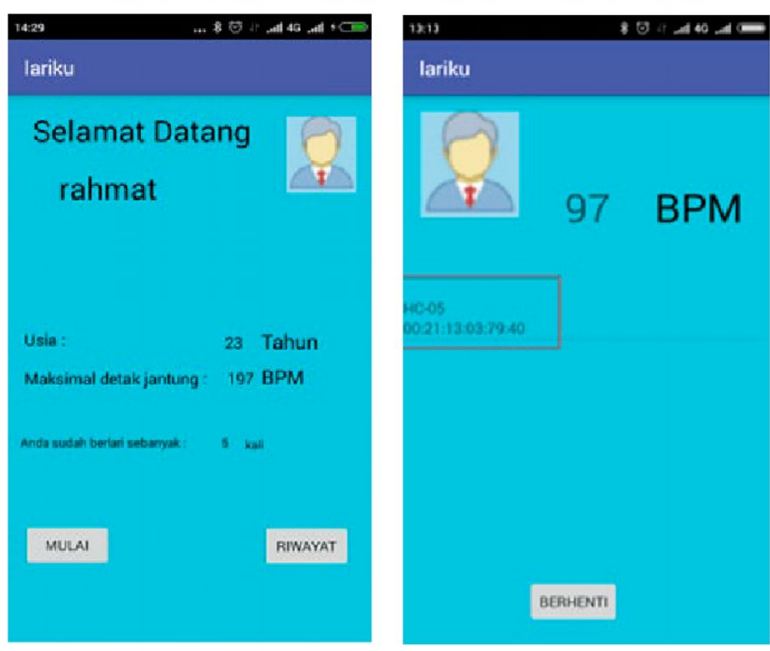

Fig. 4. Monitoring of user's heart rate during physical exercise

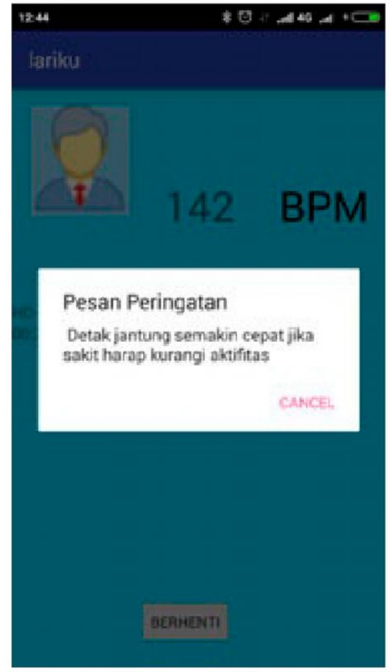

(a)

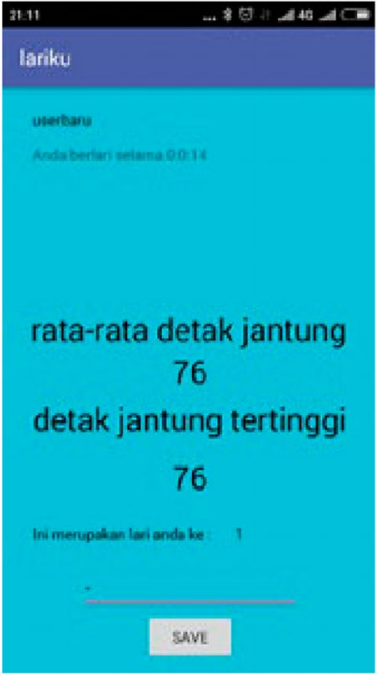

(b)
Fig. 5. (a) A warning notification is given when the user's heart rate is abnormal by the smartphone application, (b) the average number and number of beats highest heart during physical exercise.

In this test, the highest heart rate obtained is 167 BPM from a 23-year-old user with running speed reaching 13 $\mathrm{km} /$ hour. Heart rate like this can be categorised as dangerous and approaching the maximum heart rate which ranges from $85 \%$ of the user's heart rate, but it can also be categorised as harmless if the user does not feel pain in any part of their body and this running activity is not the first for them. In this test 167 BPM was obtained on the third running of 23 years old user and the user at the time of testing did not feel pain in the body. In Figure 10, the data retrieval process and the running history display on the smartphone application are shown.

In the whole test also carried out data collection on 3 in seeing the difference of the heart rate when given the same speed with the same conditions and at the same time. In this test, the subjects would be asked to run $2 \mathrm{~km}$, at every 500 meters, the subjects will get a different speed. The speed increase is set every $\mathbf{5 0 0}$ meters. The variation of speed used were $5 \mathrm{~km} /$ hour, $6 \mathrm{~km} /$ hour, and $7 \mathrm{~km} /$ hour. 
TABLE I. EXPERIMENTAL RESULTS

\begin{tabular}{|c|c|c|c|c|c|c|c|c|c|}
\hline \multirow{2}{*}{ Subject } & \multirow{2}{*}{$\begin{array}{c}\text { Age } \\
\text { (years) }\end{array}$} & \multirow{2}{*}{$\begin{array}{c}\text { Total } \\
\text { number } \\
\text { of test }\end{array}$} & \multirow{2}{*}{$\begin{array}{c}\text { Running speed } \\
\text { range }\end{array}$} & \multirow{2}{*}{$\begin{array}{c}\text { Running } \\
\text { duration }\end{array}$} & \multirow{2}{*}{$\begin{array}{c}\text { The highest } \\
\text { of heart } \\
\text { rate when } \\
\text { running }\end{array}$} & \multirow{2}{*}{$\begin{array}{c}\text { The number of } \\
\text { heartbeats is } \\
\text { beyond safe limits } \\
\text { during running }\end{array}$} & \multicolumn{3}{|c|}{$\begin{array}{c}\text { The success of alert } \\
\text { notifications }\end{array}$} \\
\hline 1 & & & & & & Yes & No & Accuracy \\
\hline 2 & 20 & 5 & $6-9 \mathrm{~km} /$ hour & $0: 15: 10$ & 153 & 4 & 4 & 0 & $100 \%$ \\
\hline 3 & 22 & 5 & $5-8 \mathrm{~km} /$ hour & $0: 16: 43$ & 146 & 3 & 3 & 0 & $100 \%$ \\
\hline 4 & 22 & 5 & $7-10 \mathrm{~km} /$ hour & $0: 16: 58$ & 151 & 5 & 5 & 0 & $100 \%$ \\
\hline 5 & 23 & 5 & $8-13 \mathrm{~km} /$ hour & $0: 14: 11$ & 167 & 4 & 4 & 0 & $100 \%$ \\
\hline 6 & 25 & 5 & $7-9 \mathrm{~km} /$ hour & $0: 15: 28$ & 159 & 4 & 4 & 0 & $100 \%$ \\
\hline 7 & 28 & 5 & $5-9 \mathrm{~km} /$ hour & $0: 18: 13$ & 157 & 4 & 4 & 0 & $100 \%$ \\
\hline
\end{tabular}

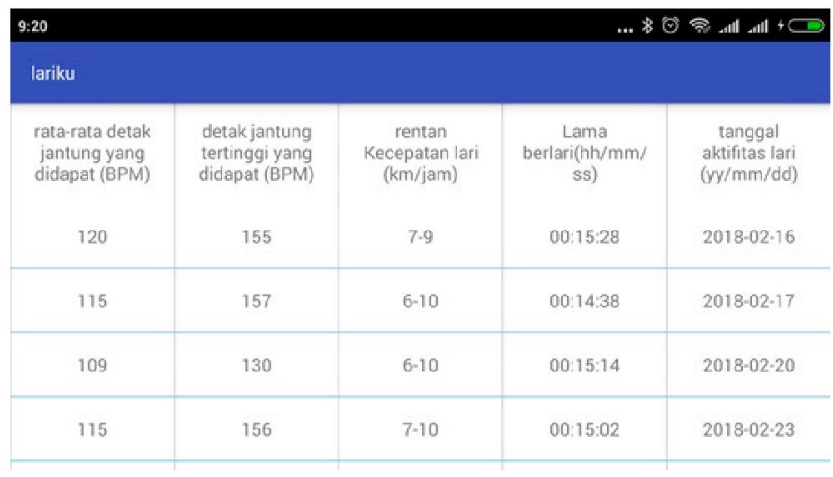

Fig. 6. Running history display on the smartphone application

Based on the testing of variations in speed, the heart rate data is affected by running speed. Based on the test results at a speed of $7 \mathrm{~km} /$ hour the subject tends to get a warning message because the user's heartbeat is beating faster. While at the speed of $6 \mathrm{~km} /$ hour and the last distance of 500 meters the user's heart rate begins to decline even though the decrease in the user's heart rate is not significant. The highest heart rate is found in 23-year-old users with a running speed of $7 \mathrm{~km} /$ hour. The test results of running speed with number of heart rate can be seen in the graph in the Figure 11. This graph shows the amount of heart rate will increase according to the increase in running speed.

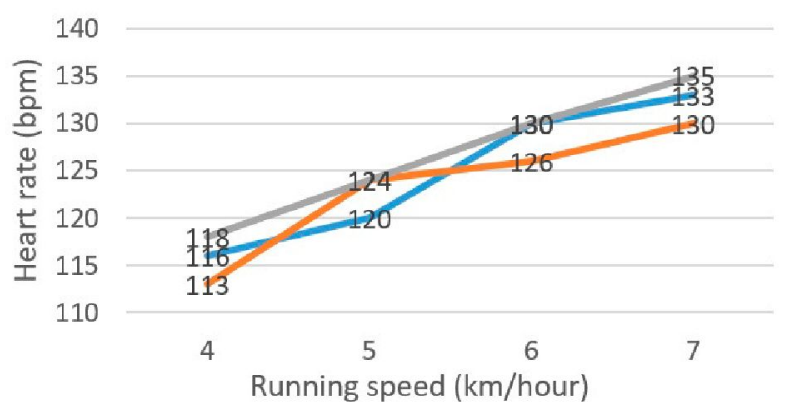

20 years old $\longrightarrow 23$ years old $\longrightarrow 25$ years old

Fig. 11. The test results of running speed with number of heart rate

Testing the accuracy of heart rate measurements was done by comparing the output of wearable device with an existing heart rate measuring device. The existing instrument used was the 1180 skmei watch. 1180 skmei is a watch that has the ability to number the heart rate while running. Measurements was made in parallel looking when the heart rate was detected by each device. The test results in Table II show the accuracy of the results of measuring the number of heartbeats on the wearable device is $95.923 \%$.

TABLE II. THE RESULTS OF MEASURING THE ACCURACY OF WEARABLE DEVICES

\begin{tabular}{|c|c|c|c|}
\hline \multirow{2}{*}{$\begin{array}{l}\text { Testing } \\
\text { to }\end{array}$} & \multicolumn{2}{|c|}{$\begin{array}{l}\text { Number of heart rate } \\
\text { (BPM) }\end{array}$} & \multirow{2}{*}{ Accuracy } \\
\hline & $\begin{array}{c}1180 \text { skmei } \\
\text { watch }\end{array}$ & $\begin{array}{c}\text { Wearable } \\
\text { device }\end{array}$ & \\
\hline 1 & 71 & 74 & 95.78 \\
\hline 2 & 72 & 69 & 95.84 \\
\hline 3 & 74 & 73 & 98.65 \\
\hline 4 & 75 & 70 & 93.4 \\
\hline 5 & 77 & 77 & 100 \\
\hline 6 & 73 & 73 & 100 \\
\hline 7 & 75 & 80 & 93.38 \\
\hline 8 & 66 & 66 & 100 \\
\hline 9 & 72 & 71 & 98.62 \\
\hline 10 & 75 & 77 & 97.24 \\
\hline 11 & 78 & 72 & 92.4 \\
\hline 12 & 79 & 83 & 94.94 \\
\hline 13 & 65 & 62 & 95.39 \\
\hline 14 & 73 & 80 & 90.42 \\
\hline 15 & 71 & 79 & 88.74 \\
\hline 16 & 76 & 77 & 98.69 \\
\hline 17 & 61 & 66 & 91.81 \\
\hline 18 & 76 & 80 & 94.74 \\
\hline 19 & 68 & 69 & 98.53 \\
\hline 20 & 85 & 86 & 99.89 \\
\hline \multicolumn{3}{|c|}{ Average of } & 95.923 \\
\hline
\end{tabular}

\section{CONCLUSION AND FUTURE WORK}

This research has succeeded in building and implementing a heart rate monitoring system using a photoplethysmograph signal to detect fatigue in running sports in real time. Based on the results of testing with variations in speed, age and runtime, the heartbeat rate is affected by age and running 
speed. When running speed increases, the heart rate also increases. The application on the Android Smartphone has successfully displayed a warning message when the heartbeat is not normal or near the maximum heart rate. In the future work, we will add other biosignal parameters for level measurement of fatigue and use the implementation of machine learning.

\section{ACKNOWLEDGMENT}

The research is supported by Faculty of Information and Technology, University of Andalas for publication. The authors thank the referee for the comments and suggestions on the earlier version of this paper.

\section{REFERENCES}

[1] J. F. Handyani; Lintong, Fransiska;Rumampuk, "Pengaruh Aktivitas Berlari Terhadap Tekanan Darah dan Suhu Pada Pria Dewasa Normal," J. e-Biomedik, vol. 4, p. 4, 2016.

[2] J. Achten and A. E. Jeukendrup, "Heart rate monitoring: Applications and limitations," Sport. Med., vol. 33, no. 7, pp. 517 $538,2003$.

[3] N. I. of Health, "Physical Activity and Your Heart," p. 44, 2006.

[4] J. Halomoan, "Analisa Sinyal EKG dengan Metoda HRV ( Heart Rate Variability ) pada Domain Waktu Aktivitas Berdiri dan Terlentang," Semin. Nas. Apl. Teknol. Inf. 2013, pp. 29-35, 2013.

[5] M. Fezari, M. Bousbia-Salah, and M. Bedda, "Microcontroller based heart rate monitor," Int. Arab J. Inf. Technol., vol. 5, no. 4, pp. $153-157,2008$.

[6] C. T. Chu, H. K. Chiang, and J. J. Hung, "Dynamic heart rate monitors algorithm for reflection green light wearable device," ICIIBMS 2015 - Int. Conf. Intell. Informatics Biomed. Sci., pp. 438-445, 2016.

[7] H. R. Mean, "Monitoring Exercise Intensity Using Heart Rate," p. 92123, 2001.

[8] D. Ichwana, "Smart Parking Payment Menggunakan Near Field Communication ( NFC)," no. November, pp. 26-27, 2016.

[9] D. Ichwana and W. Syahputra, "Sistem Pembayaran Parkir Menggunakan NEAR FIELD COMMUNICATION Berbasis ANDROID dan Teknologi INTERNET OF THINGS," J. Teknol. dan Sist., vol. 03, no. 01, pp. 153-164, 2017.

[10] D. Ichwana, R. Aisuwarya, S. Ardopa, and I. Purnama, "Sistem Cerdas Reservasi dan Pemantauan Parkir pada Lokasi Kampus Berbasis Konsep Internet of Things," J. Teknol. dan Sist. Komput., vol. 6, no. 2, p. 57, 2018.

[11] Z. Zhang, Z. Pi, S. Member, and B. Liu, "TROIKA : A General Framework for Heart Rate Monitoring Using Wrist-Type Photoplethysmographic Signals During Intensive Physical Exercise," vol. 62, no. 2, pp. 522-531, 2015.

[12] V. Jindal, "Integrating mobile and cloud for PPG signal selection to monitor heart rate during intensive physical exercise," Proc. Int. Work. Mob. Softw. Eng. Syst. - MOBILESoft '16, pp. 36-37, 2016.

[13] Z. Zhang, "Heart rate monitoring from wrist-type photoplethysmographic (PPG) signals during intensive physical exercise," 2014 IEEE Glob. Conf. Signal Inf. Process. Glob. 2014, pp. 698-702, 2014

[14] Z. Zhang, "Photoplethysmography-based heart rate monitoring in physical activities via joint sparse spectrum reconstruction," IEEE Trans. Biomed. Eng., vol. 62, no. 8, pp. 1902-1910, 2015.

[15] M. Boloursaz, E. Asadi, M. Eskandari, S. Kiani, and S. Members, "Heart Rate Tracking using Wrist - Type Photoplethysmographic ( PPG ) Signals during Physical Exercise with Simultaneous Accelerometry," IEEE Signal Process. Lett., vol. 23, no. 2, pp. 227-231, 2016.
[16] A. K. Ahmadi, P. Moradi, M. Malihi, S. Karimi, and M. B. Shamsollahi, "Heart Rate monitoring during physical exercise using wrist-type photoplethysmographic (PPG) signals," Proc. Annu. Int. Conf. IEEE Eng. Med. Biol. Sac. EMBS, vol. 2015Novem, pp. 6166-6169, 2015.

[17] A. Temko, "Accurate Heart Rate Monitoring during Physical Exercises Using PPG," IEEE Trans. Biomed. Eng., vol. 64, no. 9, pp. 2016-2024, 2017.

[18] K. O. Koç, K. Polat, E. Ve Elektronik, M. Bölümü, A. Zzet, and B. Üniversitesi, “Akll Telefon Kameras Kullanarak Kalp Hz Tahmini için MATLAB GUI Tasarm MATLAB GUI Design for Heart Rate Monitoring Using Smart Phone Camera," pp. 3-6, 2017.

[19] Y. J. Kim, H. S. Jang, C. S. Byun, and B. S. Choi, "Development of u-health monitoring system using PPG sensor," Int. Conf. Electron. Inf. Commun. ICEIC 2018, vol. 2018-Janua, pp. 1-2, 2018. 